\title{
Selection of Communication Routes in Agriculture Equipment Company
}

\author{
Jana Křečková, Jan Rydval, Helena Brožová, Andrea Hornická
}

Faculty of Economics and Management, Czech University of Life Sciences in Prague, Czech Republic

\begin{abstract}
Many publications describe problems in businesses and project management that are caused by communication. Team communication is a very complicated process full of soft aspects. One of basic problems represents a choice of an appropriate communication route kind useful for messages transmission between the team members as sources and recipients. It is a complex issue because of necessity to evaluate individual communication routes from many different perspectives. Therefore the suitable communication route of team members can be selected by a multicriterial mathematical model. Since communication can be understood as a distribution of messages, the appropriate model form can be based on the distribution model. The proposed model is derived from the three-dimensional transportation problem. The article discusses the possibility of this approach on the case study of communication modelling in the field of agriculture. Specifically, it is constructed and solved a model of communication problem for small team of agriculture equipment dealers.
\end{abstract}

\section{Keywords}

Team, communication, message, communication route, three-dimensional transportation model, agriculture equipment dealers.

Křečková, J., Rydval, J., Brožová, H. and Hornická, A. (2017) "Selection of Communication Routes in Agriculture Equipment Company", AGRIS on-line Papers in Economics and Informatics, Vol. 9, No. 4, pp. 69-79. ISSN 1804-1930. DOI 10.7160/aol.2017.090407.

\section{Introduction}

Communication supports mutual understanding representing an important tool in leading of the company (Zulch, 2014). Results of many scientific studies confirm that high-quality communication and its effective coordination is necessary to achieve better performance (Brill et al., 2006; Hsu et al., 2012; Kerzner, 2013). Kerzner (2013) understands communication not only as a means of ensuring that the right person gets the right information at the right time but also as a cost-effective manner. In addition to a cost of communication, its scope, time, and quality, also interrelation among these three indicators are very important for effective management (Zulch, 2014; Kotzé et al., 2008).

In addition to the above mentioned communication factors, the manner of communication performing is very important. Communication between members of the team can take place directly or indirectly. According to Hoegl and Gemuenden (2001), use of indirect communication (that is the use of mediation in communication) is timeconsuming and, therefore, it increases a likelihood of incorrect transmission of information. On the other hand, Melnik and Maurer (2004) investigated the impact of direct communication on effective knowledge sharing and concluded that face-to-face communication facilitates achieving a higher team working speed as it enables richer communication due to ability of transmitting multivariate signals (e.g. body language, melody, height, and voice depth, etc.).

Lingard et al. (2006) paid attention to lack of knowledge of the relationship between specific communication practices and possibility to improve collaborative working practices. The authors surveyed a three-member team and, subsequently, found that changing communication patterns influences the team's attention and behaviour. Unfortunately, current publications do not provide either detailed description of applicable methods of operation research or critical evaluation of reasons why a particular application of various methods was successful or unsuccessful (Hämäläinen et al., 2013). Zionts (1979) solved a problem of quantifying communication by multiple-criteria decision-making taking into account cost and quality as the main criteria. 
However, multi-criteria decision-making methods do not provide any optimal solution but only a kind of compromise between a set of criteria (Bolat et al., 2014). The model of system dynamics used by Saleh et al. (2010) and Hämäläinen et al. (2013) examined behavioural effects associated with group interaction and communication, changes in the target behaviour, and changes of interest. Kennedy et al. (2011) and Katz and Allen (1982) used empirical methods that highlighted the importance of communication in work performance. Later, Kennedy et al. (2017) applied a linear optimization model of a communication process between members of two teams.

The purpose of this study is to propose an appropriate operational research model of team communication and help to achieve better understanding communication within a team. This model structure is based on the three-dimensional transportation problem and the Kennedy model (Kennedy et al., 2017). They used linear programming, examined selection of optimal communication ways between two teams across different communication routes, and other conditions. Their model contains capacity equations limiting the messages communicated from and to the team members across different communication routes. Further, there are also the flow constraints representing messages demands over the specific communication routes and, concurrently, non-negativity constraints. The model also includes the objective functions minimizing time, cost, and negative quality function, and aggregation of these objective functions.

This article is divided into the three following sections:

- Materials and Methods describing assumptionsused building the communication model; specifically, it is a description of the two and three-dimensional transportation problems; further, the communication problem of agriculture equipment dealers and its model are described;

- Results and Discussion analysing results generated by the model of the optimal communication structure according to specified conditions;

- Conclusion offering a summary of the findings, and comparison of suggested model with the Kennedy model (Kennedy et al., 2017).

\section{Materials and methods}

\section{Transportation problems}

The applications from the field of the linear optimization model dealing with transportation of products from several sources (or suppliers) to several destinations (or receivers) by the same cost of transport are commonly called the transportation problem. This model can be used for representing more general assignment and scheduling problems as well as transportation and distribution problems (Dantzig, 1955; Šubrt, 1999). Two common objectives of these problems represent either (i) minimizing transportation costs of shipping the goods from $m$ sources to $n$ destinations or (ii) maximizing the profit for shipping the goods from $m$ sources to $n$ destinations. Let suppliers offer non-zero amounts $a_{i}, i=1, \ldots, m$ and the receivers require amounts $b_{j}, j=1, \ldots, n$, respectively. The problem is balanced when the overall supply is equal to overall demand. Each route from each supplier to each receiver is evaluated with a cost coefficient $c_{i j}, i=1, \ldots m, j=1, . ., n$. The simple transportation model is formulated as (1):

$$
\min \sum_{i=1}^{m} \sum_{j=1}^{n} c_{i j} x_{i j}
$$

subject to

$\begin{array}{ll}\sum_{j=1}^{n} x_{i j}=a_{i}, & i=1, \ldots, m \\ \sum_{i=1}^{m} x_{i j}=b_{j}, & j=1, \ldots, n\end{array}$

$x_{i j} \geq 0, \quad i=1, \ldots, m, j=1, \ldots, n$

where the decision variables $x_{i j}$ represent the amounts to be transported from source locations $i$ to target destinations $j$. The solution for simple transportation problem exists if the problem is balanced, if the total demand is equal to the total source capacity.

\section{Three-dimensional transportation model}

The aim of the three-dimensional transportation model (3DTM) is to find an optimal transportation plan between sets of sources and destinations using different types of transport. Let the suppliers offer non-zero amounts $a_{i}, i=1, \ldots, m$ and, concurrently, the target locations demand amounts $b_{j}, j=1, \ldots, n$, respectively, and $w_{k}, k=1,2, \ldots, p$ are the capacities of a different type of transport. The problem is balanced if the overall supply equals overall demand. Each route from any supplier to any target 
location is evaluated with the cost coefficient $c_{i j k}$, $i=1, \ldots m, j=1, . ., n, k=1, \ldots, p$. The threedimensional transportation model can be formulated in two forms, the planar formulation corresponds to the formulation of simple transportation model, see (2):

$$
\min \sum_{i=1}^{m} \sum_{j=1}^{n} \sum_{k=1}^{p} c_{i j k} x_{i j k}
$$

subject to

$$
\begin{aligned}
& \sum_{j=1}^{n} \sum_{k=1}^{p} x_{i j k}=a_{i}, \quad i=1, \ldots, m \\
& \sum_{i=1}^{m} \sum_{k=1}^{p} x_{i j k}=b_{j}, \quad j=1, \ldots, n \\
& \sum_{i=1}^{m} \sum_{j=1}^{n} x_{i j k}=w_{k}, \quad k=1,2, \ldots, p \\
& x_{i j k} \geq 0, \quad i=1, \ldots, m, j=1, \ldots, n, k=1,2, \ldots, p
\end{aligned}
$$

where the decision variables $x_{i j k}$ represent the amounts to be transported from source locations $i$ to target destinations $j$ using k type of transport.

The three-dimensional transportation model can be also formulated in axial form (3):

$$
\min \sum_{i=1}^{m} \sum_{j=1}^{n} \sum_{k=1}^{p} c_{i j k} x_{i j k}
$$

subject to

$$
\begin{aligned}
& \sum_{k=1}^{p} x_{i j k}=a_{i j}, \quad i=1,2, \ldots, m, j=1,2, \ldots, n \\
& \sum_{i=1}^{m} x_{i j k}=b_{j k}, \quad j=1,2, \ldots, n, k=1,2, \ldots, p \\
& \sum_{j=1}^{n} x_{i j k}=w_{i k}, \quad i=1,2, \ldots, m, k=1,2, \ldots, p \\
& x_{i j k} \geq 0, \quad i=1, \ldots, m, j=1, \ldots, n, k=1,2, \ldots, p
\end{aligned}
$$

where the decision variables $x_{i j k}$ represent the amounts to be transported from source locations $i$ to target destinations $j$ using $k$ type of transport, transported amounts from source $i$ to destination $j$ by all types of transport $a_{i j}, i=1, \ldots, m, j=1, \ldots, n$, transported amounts from all sources to destination $j$ by $\mathrm{k}$-th type of transport $b_{j k}, j=1, \ldots, n$, $k=1,2, \ldots, p$, and transported amounts from source $i$ to all destinations by k-th type of transport $w_{i k}, \quad i=1, \ldots, m, k=1,2, \ldots, p$. Each route from any supplier to any target location is evaluated with the cost coefficient $c_{i j k}, i=1, \ldots m, j=1, . ., n$, $k=1, \ldots, p$.

Although the conditions of existence of solutions for the planar formulation of the problem are natural, in the case of axial formulation the situation is more complex. The conditions for the existence of solutions of this formulation were described, for example, by Morávek and Vlach (1967) or Vlach (1986).

The variables $x_{i j k}, i=1, \ldots m, j=1, . ., n, k=1, \ldots, p$ of the 3DTM create a communication threedimensional cube in contrast with a simple transport problem where variables $x_{i j}, i=1, \ldots m$, $j=1, . ., n$ form a two-dimensional matrix. The view of the three-dimensional cube is possible in three ways - by planes, columns, and cells (Figure 1). The first formulation of 3DTM (2) is called the planar formulation because the solution cube is seen as a set of planar cuts. The planar cut means a cut fixing one coordinate. The planar formulation defines the capacity of sources or transport types or demands. Similarly, it is possible to define the axial formulation of 3DTM (3) as an axial cut, which means fixing two coordinates. This is much more restrictive model formulation form because more precise information on problem solution is needed. The cellular cuts represent the smallest dimensionless element - one value in solution cube; it is a cut fixing three coordinates. Cellular formulation of model is unreasonable because it actually represents the only solution of the whole problem.

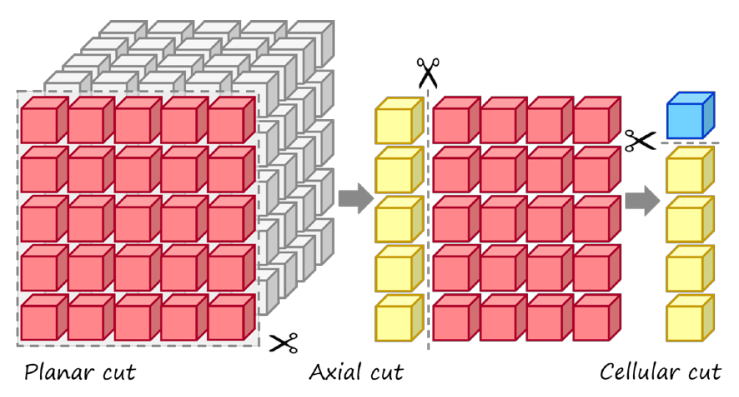

Source: own processing (inspired by Urbanek, 2014)

Figure 1: Planar, axial and cellular cuts.

\section{Results and discussion}

\section{Model of team communication routes}

The problem of team usage of communication routes for messages distribution represents issues of selection of communication routes of a message transfer from and to team members. These communication routes are selected from a set 
of communication routes according to three specific criteria - time, cost and quality of message transfer.

The problem of finding the best structure of team communication is not focused on the content of messages. Because it is not important what specific message is passed, we will continue to consider the reports are homogeneous.

Since we find the basic structure of communication and we assume the average amount of transmitted messages, we assume that messages can be divided and their parts can be transmitted through various communication routes. For this reason, we do not require integer solution.

Furthermore, we assume that each member of the team at the same time acts both as a sender and as a recipient of messages. Therefore, the number of senders and recipients is the same.

Since we start from the average number of messages sent and received by individual members of the team, we do not consider the loss of messages or unwillingness to communicate, we assume that the total number of messages sent and the total number of messages received are equal.

The proposed model serves for selection of the best communication routes based on their evaluation and consequently for identification how many communication units will be transmitted between team members via selected communication routes.

We consider a group $T$ consisting of team members $T=\left(T_{l}, T_{2}, \ldots, T_{n}\right)$ having number of the messages $\left(s_{1}, s_{2}, \ldots, s_{n}\right)$ to be sent to the team members and number of the messages $\left(r_{l}, r_{2}, \ldots, r_{n}\right)$ to be received from other team members. The communication volume will be measured as a number of messages containing exclusive data, information, tasks, and knowledge necessary for work performing.

A suitable mathematical formulation of this problem can be derived from the three-dimensional transportation model (3DTM). The communication problem will consist of the senders (the first dimension, sources) and the recipients (the second dimension, destinations) of messages, and the communication routes (the third dimension, types of transport).

The model of the team communication routes works with three indexed variables determining the amount of the messages communicated between the sender and the recipient via the route. The transferred number of the messages from the sender $\left(T_{i}\right)$ to the recipient $(T j)$ via the selected communication route $\left(W_{k}\right)$ is denoted as $x_{i j k}$.

The initial data are the total number of the messages $\left(s_{1}, s_{2}, \ldots, s_{n}\right)$ to be sent by senders and the total number of the messages $\left(r_{p}, r_{2}, \ldots, r_{n}\right)$ received by recipients. In addition, we consider a set $W$ of communication routes $W=\left(W_{1}, W_{2}, \ldots, W_{p}\right)$ with maximal or minimal flows $\left(w_{p}, w_{2}, \ldots, w_{p}\right)$ where $p$ denotes the number of the communication routes available for communication within the team (Table 1).

At the same time, the expected average week amount of the messages $m_{i j}, i=1, \ldots n, j=1, \ldots, n$ the team members passing on is known in advance (Table 2). Very often, some of the amount of the messages $o_{i k}$, $j=1, \ldots, n, k=1, \ldots, p$ being sent from all senders to specific recipient via specific communication route or the amount of the messages $q_{i k}, i=1, \ldots$, $n, k=1, \ldots, p$ being sent from specific sender to all recipient via specific communication route are required.

$$
\begin{array}{c|c|}
\cline { 2 - 2 } \mathrm{T}_{1} & \mathrm{~s}_{1} \\
\mathrm{~T}_{2} & \mathrm{~s}_{2} \\
\ldots & \ldots \\
\mathrm{T}_{\mathrm{n}} & \mathrm{s}_{\mathrm{n}} \\
\end{array}
$$

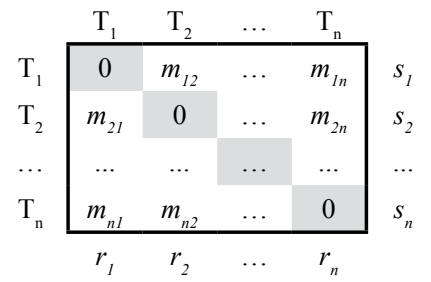

Source: own processing

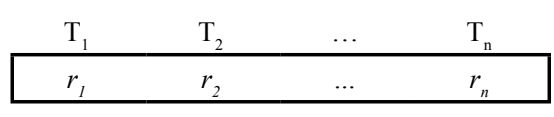

Table 1: Planar input data tables.

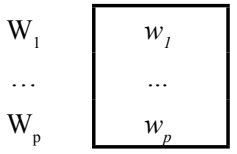

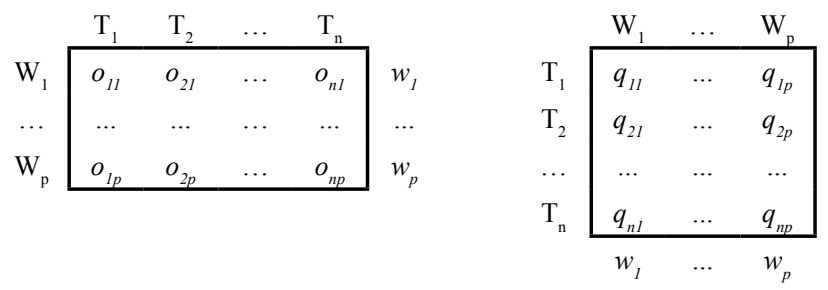

Table 2: Axial input data tables. 
Similarly, in some cases, the amount of the messages $v_{i j k}, i=1, \ldots n, j=1, \ldots, n, k=1, \ldots$, $p$ for specific sender, receiver, and route are also required (Table 3 ).

Description of the conditions of planar, axial, and cellular cuts

We can formulate three basic types of constraints that represent naturally existing conditions of communication.

\section{Planar conditions}

The first type of these constraints corresponds to the limitations based on 3DTM planar cuts (2). The first group of planar conditions are the flow constraints representing the expected average weekly amount of the sent messages (4).

$\sum_{j=1}^{n} \sum_{k=1}^{p} x_{i j k}=s_{i}, i=1, \ldots, n$

The second group of planar conditions are also the flow constraints derived from the expected amount of the received messages (5).

$\sum_{i=1}^{n} \sum_{k=1}^{p} x_{i j k}=r_{j}, j=1, \ldots, n$

The third group of planar conditions represents the required minimal amount of the messages transmitted by the communications routes. The requirement for minimum use of individual communication routes is given by these conditions (6).

$\sum_{i=1}^{n} \sum_{j=1}^{n} x_{i j k} \geq w_{k}, k=1, \ldots, p(6)$

\section{Axial conditions}

The second type of the constraints in the communication model are based on the 3DTM axial cuts (3). The first of these limitations is the flow constraint representing communication between the sender and the recipient of the message across all the communication routes. If the solution fulfils these constraints (7), the previous constraints (4) and (5) are also satisfied and need not be used.

$$
\sum_{k=1}^{p} x_{i j k}=m_{i j}, i=1, \ldots, n, j=1, \ldots, n
$$

When regular meetings are held in the company, the axial conditions can also describe these requirement conditions. The meetings mean communication face to face through which one of the team members sends the messages to the other team members (8) and, vice versa, through which one of the team members receives the messages from the other team members (9). Generally, such constraints have the following form:

$$
\begin{aligned}
& \sum_{i=1}^{n} x_{i j k} \geq o_{j k}, \quad j=1,2, \ldots, n, k=1,2, \ldots, p \\
& \sum_{j=1}^{n} x_{i j k} \geq q_{i k \prime}, \quad i=1,2, \ldots, n, k=1,2, \ldots, p
\end{aligned}
$$

\section{Cellular conditions}

The last type of constraints in the communication model contains the limitations based on the 3DTM cellular cuts. These are the conditions for communication between two specific team members through a specific communication route (10). General form of such constraints is

$x_{i j k} \geq v_{i j k}, i=1,2, \ldots, n, j=1,2, \ldots, n, k=1,2, \ldots, p$

These constraints $(8,9$, and 10$)$ may not be stated for all elements of problem.

At the same time, there is a prerequisite for this team member not to communicate with himself (11).

$$
x_{i i k}=0, i=1, \ldots n, k=1, \ldots, p
$$

For the variables, the non-negative condition has to be met (12).

$x_{i j k} \geq 0$

\section{Objective functions}

Finally, the communication time, communication cost and quality of communication via different

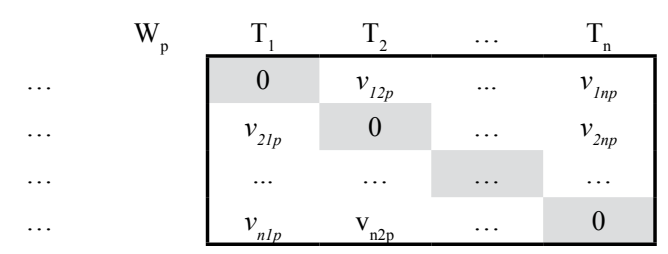

Source: own processing

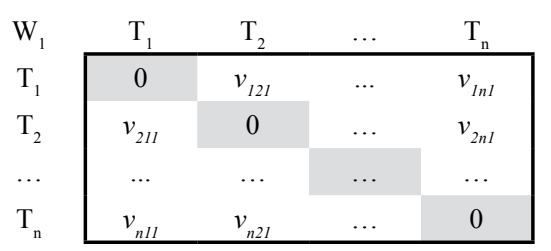

Table 3: Cellular input data tables. 
communication routes of the transmitted message from the sender $\left(T_{i}\right)$ to the recipient $\left(T_{j}\right)$ via the selected communication route $\left(W_{k}\right)$ are denoted as $x_{i j k}^{c}, x_{i j k}^{t}, x_{i j k}^{q}$. The three objective functions (13) represent a linear combination of the variables and their costs coefficients. This functions are of a minimizing or a maximizing character and can be formulated as follows:

$$
\begin{aligned}
& \min \sum_{i}^{n} \sum_{j}^{n} \sum_{k}^{p} c_{i j k}^{c} x_{i j k} \\
& \min \sum_{i}^{n} \sum_{j}^{n} \sum_{k}^{p} c_{i j k}^{t} x_{i j k} \\
& \max \sum_{i}^{n} \sum_{j}^{n} \sum_{k}^{p} c_{i j k}^{q} x_{i j k}
\end{aligned}
$$

Selection of the best communication routes for agriculture equipment dealers

This case study was based on data from one small Czech company selling agricultural equipment. The core team of this company consists of the owner (O), economist (EC), and two dealers (1D, 2D). Since the company staff has suffered from communication problems and lack of the information transfer, the company owner needs to set some rules of the corporate communication. These rules should provide sufficient information flow to the company members at minimum cost. The problem formulation is based on the information obtained within the frame of consultation with the owner of the company. The company owner assumes that realizing regular meetings, maybe once a week, would be appropriate. In addition, the owner prefers electronic communication (via e-mail) since it allows the recording of transferred messages. The company uses telephone (P), e-mail (E), and face-to-face (F2F) communication routes. The owner of the company estimates the amount of the messages probably transmitted within the company in the period of one week (Table 4).

\section{Planar conditions}

Within the company communication, the usual

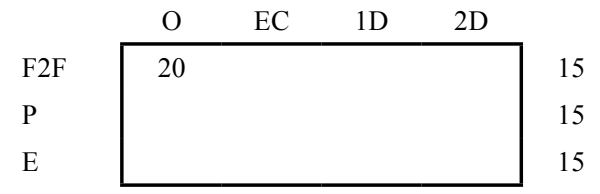

Source: own processing

Table 5: Axial input data for communication problem of agriculture equipment dealers (only non-zero values). amount of messages must be transmitted. The volume of messages that each team member must pass on is in the column s in Table 4 and, similarly, the volume of messages that each team member must receive is in the row $r$ in Table 4. The last group of planar conditions represents usage of each communication route at least in the range of 15 messages (Table 5).

\begin{tabular}{l|cccc|c} 
& O & EC & $1 D$ & $2 D$ & \multicolumn{1}{c}{50} \\
\cline { 2 - 6 } owner (O) & & 20 & 15 & 15 & 50 \\
economist (EC) & 20 & & 5 & 5 & 30 \\
$1^{\text {st }}$ dealer (1D) & 10 & 5 & & 7 & 22 \\
$2^{\text {nd }}$ dealer (2D) & 10 & 5 & 7 & & 22 \\
\cline { 2 - 5 } & 40 & 30 & 27 & 27 &
\end{tabular}

Source: own processing

Table 4: Planar input data for communication problem of agriculture equipment dealers (only non-zero values).

\section{Axial conditions}

The communication between the sender and recipient across all the communication routes must correspond to the values in Table 5. Within the meetings, i.e. face-to-face communication routes, the company owner transmits at least 20 communication messages. The last condition is similar however at least the same number of messages must be received.

\section{Cellular conditions}

The cellular conditions ensure the owner communication with each member of the team during one meeting. There must be at least three messages from the owner and to the owner (Table 6).

\begin{tabular}{l|cccc|} 
& $\mathrm{O}$ & $\mathrm{EC}$ & $1 \mathrm{D}$ & $2 \mathrm{D}$ \\
\cline { 2 - 5 } & & 3 & 3 & 3 \\
owner (O) & 3 & & & \\
economist (EC) & 3 & & & \\
$1^{\text {st }}$ dealer (1D) & 3 & & & \\
$2^{\text {nd }}$ dealer (2D) & 3 & & & \\
\cline { 2 - 4 } & & &
\end{tabular}

Source: own processing

Table 6: Cellular input data for communication problem of agriculture equipment dealers (only non-zero values).

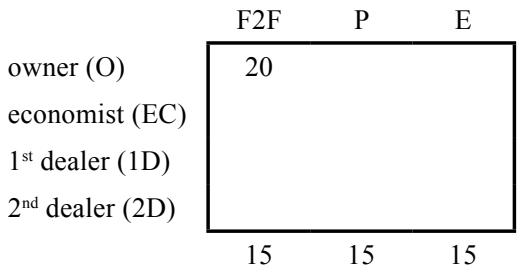




\section{Objective functions}

The owner would like to find a solution of the problem in terms of three criteria: time, cost, and quality. All the criteria are equally important to him. The individual communication routes were evaluated using Saaty's pairwise comparison method. The values for the individual objective functions are shown in Table 7.

Since all the criteria have to be assumed for decision making, we need to use some multiple criteria approach. In this case study we calculated so-called partial optimal solutions, i.e. consecutively three optimal solutions of the model with a single criterion. After that, the final compromise solution was obtained as the linear aggregation (LA) of the partial optimal solutions $x_{i j k}^{t}$ (minimization of time - T), $x_{i j k}^{c}$ (minimization of the cost - C), and $x_{i j k}^{q}$ (maximization of quality - Q). The compromise solution $x_{i j k}$ is calculated using the following formula (14).

$$
x_{i j k}=\frac{x_{i j k}^{c}+x_{i j k}^{t}+x_{i j k}^{q}}{3}, i=1, \ldots n, j=i, k=1, \ldots, p
$$

\section{Results}

Using the above-mentioned three-dimensional transportation model with supposed three objective functions, three partial optimal solutions were found (in the following tables in columns T, C, Q) and compromise solution was calculated (column LA).

The recommended use of the face-to-face communication route is shown in Table 8 . This is the second most used communication route. The face-to-face communication results correspond to the requirement of using the face-to-face communication based mainly on meetings held together with the company's owner. At these meetings, it is anticipated that each employee reports messages to the owner and, at the same time, the owner reports messages to other team members. For this reason, the owner is the most burdened by the messages. Except the meetings, there is no face-to-face communication because the team members stay in different workplace locations. The total number of weekly messages passing through this route is 40 .

Using the communication route via a phone is shown in Table 9. This is the least used communication route through which 33 weekly messages are distributed. Infrequent use of this communication route may be a result of the unique use of the phone when the team members decide to prefer quality and cost criteria of communication and choose the e-mail communication instead.

The zero values below the main diagonal at some

\begin{tabular}{|c|c|c|c|c|c|c|c|c|c|c|c|c|}
\hline \multirow{2}{*}{ Time $(T)-\min$} & \multicolumn{4}{|c|}{$\mathrm{F} 2 \mathrm{~F}$} & \multicolumn{4}{|c|}{$\mathrm{P}$} & \multicolumn{4}{|c|}{ E } \\
\hline & $\mathrm{O}$ & $\mathrm{EC}$ & $1 \mathrm{D}$ & $2 \mathrm{D}$ & $\mathrm{O}$ & $\mathrm{EC}$ & $1 \mathrm{D}$ & $2 \mathrm{D}$ & $\mathrm{O}$ & $\mathrm{EC}$ & $1 \mathrm{D}$ & $2 \mathrm{D}$ \\
\hline owner $(\mathrm{O})$ & & 0.51 & 0.51 & 0.51 & & 0.10 & 0.10 & 0.10 & & 0.39 & 0.39 & 0.39 \\
\hline economist (EC) & 0.51 & & 0.51 & 0.51 & 0.10 & & 0.10 & 0.10 & 0.39 & & 0.39 & 0.39 \\
\hline $1^{\text {st }}$ dealer (1D) & 0.51 & 0.51 & & 0.51 & 0.10 & 0.10 & & 0.10 & 0.39 & 0.39 & & 0.39 \\
\hline $2^{\text {nd }}$ dealer $(2 \mathrm{D})$ & 0.51 & 0.51 & 0.51 & & 0.10 & 0.10 & 0.10 & & 0.39 & 0.39 & 0.39 & \\
\hline
\end{tabular}

\begin{tabular}{|c|c|c|c|c|c|c|c|c|c|c|c|c|}
\hline \multirow{2}{*}{ Cost $(C)-\min$} & \multicolumn{4}{|c|}{$\mathrm{F} 2 \mathrm{~F}$} & \multicolumn{4}{|c|}{$\mathrm{P}$} & \multicolumn{4}{|c|}{$\mathrm{E}$} \\
\hline & $\mathrm{O}$ & $\mathrm{EC}$ & $1 \mathrm{D}$ & $2 \mathrm{D}$ & $\mathrm{O}$ & $\mathrm{EC}$ & $1 \mathrm{D}$ & $2 \mathrm{D}$ & $\mathrm{O}$ & $\mathrm{EC}$ & $1 \mathrm{D}$ & $2 \mathrm{D}$ \\
\hline owner (O) & & 0.73 & 0.73 & 0.73 & & 0.19 & 0.19 & 0.19 & & 0.08 & 0.08 & 0.08 \\
\hline economist (EC) & 0.73 & & 0.73 & 0.73 & 0.19 & & 0.19 & 0.19 & 0.08 & & 0.08 & 0.08 \\
\hline $1^{\text {st }}$ dealer (1D) & 0.73 & 0.73 & & 0.73 & 0.19 & 0.19 & & 0.19 & 0.08 & 0.08 & & 0.08 \\
\hline $2^{\text {nd }}$ dealer (2D) & 0.73 & 0.73 & 0.73 & & 0.19 & 0.19 & 0.19 & & 0.08 & 0.08 & 0.08 & \\
\hline
\end{tabular}

\begin{tabular}{|c|c|c|c|c|c|c|c|c|c|c|c|c|}
\hline \multirow{2}{*}{ Quality (Q) - max } & \multicolumn{4}{|c|}{$\mathrm{F} 2 \mathrm{~F}$} & \multicolumn{4}{|c|}{$\mathrm{P}$} & \multicolumn{4}{|c|}{$\mathrm{E}$} \\
\hline & $\mathrm{O}$ & $\mathrm{EC}$ & $1 \mathrm{D}$ & $2 \mathrm{D}$ & $\mathrm{O}$ & $\mathrm{EC}$ & $1 \mathrm{D}$ & $2 \mathrm{D}$ & $\mathrm{O}$ & $\mathrm{EC}$ & $1 \mathrm{D}$ & $2 \mathrm{D}$ \\
\hline owner (O) & & 0.29 & 0.29 & 0.29 & & 0.05 & 0.05 & 0.05 & & 0.66 & 0.66 & 0.66 \\
\hline economist (EC) & 0.29 & & 0.29 & 0.29 & 0.05 & & 0.05 & 0.05 & 0.66 & & 0.66 & 0.66 \\
\hline $1^{\text {st }}$ dealer (1D) & 0.29 & 0.29 & & 0.29 & 0.05 & 0.05 & & 0.05 & 0.66 & 0.66 & & 0.66 \\
\hline $2^{\text {nd }}$ dealer $(2 D)$ & 0.29 & 0.29 & 0.29 & & 0.05 & 0.05 & 0.05 & & 0.66 & 0.66 & 0.66 & \\
\hline
\end{tabular}

Source: own processing

Table 7: Objective functions coefficients - evaluation of communication routes (only non-zero values). 


\begin{tabular}{|c|c|c|c|c|c|c|c|c|c|c|c|c|c|c|c|c|c|c|c|c|}
\hline \multirow{2}{*}{$\mathrm{F} 2 \mathrm{~F}$} & \multicolumn{4}{|c|}{ owner (O) } & \multicolumn{4}{|c|}{ economist (EC) } & \multicolumn{4}{|c|}{$1^{\text {st }}$ dealer (1D) } & \multicolumn{4}{|c|}{$2^{\text {nd }}$ dealer (2D) } & \multirow{2}{*}{$\mathrm{T}$} & \multirow{2}{*}{$\mathrm{C}$} & \multirow{2}{*}{ Q } & \multirow{2}{*}{ LA } \\
\hline & $\mathrm{T}$ & $\mathrm{C}$ & Q & LA & $\mathrm{T}$ & $\mathrm{C}$ & $\mathrm{Q}$ & $\mathbf{L A}$ & $\mathrm{T}$ & $\mathrm{C}$ & Q & $\mathbf{L A}$ & $\mathrm{T}$ & $\mathrm{C}$ & Q & LA & & & & \\
\hline $\mathrm{O}$ & 0 & 0 & 0 & $\mathbf{0}$ & 3 & 3 & 10 & 5.33 & 14 & 3 & 7 & 8 & 3 & 14 & 3 & 6.67 & 20 & 20 & 20 & 20 \\
\hline $1 \mathrm{D}$ & 7 & 7 & 3 & 5.67 & 0 & 0 & 0 & $\mathbf{0}$ & 0 & 0 & 0 & 0 & 0 & 0 & 0 & $\mathbf{0}$ & 7 & 7 & 3 & 5.67 \\
\hline $2 \mathrm{D}$ & 10 & 10 & 3 & 7.67 & 0 & 0 & 0 & $\mathbf{0}$ & 0 & 0 & 0 & $\mathbf{0}$ & 0 & 0 & 0 & $\mathbf{0}$ & 10 & 10 & 3 & 7.67 \\
\hline
\end{tabular}

Source: own processing

Table 8: Recommended use of face-to-face communication route.

\begin{tabular}{|c|c|c|c|c|c|c|c|c|c|c|c|c|c|c|c|c|c|c|c|c|}
\hline \multirow{2}{*}{$\mathrm{F} 2 \mathrm{~F}$} & \multicolumn{4}{|c|}{ owner $(\mathrm{O})$} & \multicolumn{4}{|c|}{ economist (EC) } & \multicolumn{4}{|c|}{$1^{\text {st }}$ dealer (1D) } & \multicolumn{4}{|c|}{$2^{\text {nd }}$ dealer $(2 D)$} & \multirow{2}{*}{$\mathrm{T}$} & \multirow{2}{*}{$\mathrm{C}$} & \multirow{2}{*}{$Q$} & \multirow{2}{*}{ LA } \\
\hline & $\mathrm{T}$ & $\mathrm{C}$ & Q & LA & $\mathrm{T}$ & $\mathrm{C}$ & Q & $\mathbf{L A}$ & $\mathrm{T}$ & $\mathrm{C}$ & Q & LA & $\mathrm{T}$ & $\mathrm{C}$ & Q & LA & & & & \\
\hline $\mathrm{O}$ & 0 & 0 & 0 & 0 & 17 & 0 & 10 & 9 & 1 & 0 & 0 & 0.33 & 12 & 0 & 0 & 4 & 30 & 0 & 10 & 13.33 \\
\hline $1 \mathrm{D}$ & 3 & 0 & 0 & 1 & 0 & 0 & 0 & $\mathbf{0}$ & 0 & 0 & 0 & $\mathbf{0}$ & 7 & 7 & 0 & 4.67 & 10 & 7 & 0 & 5.67 \\
\hline $2 \mathrm{D}$ & 0 & 0 & 0 & $\mathbf{0}$ & 5 & 5 & 5 & 5 & 0 & 0 & 0 & $\mathbf{0}$ & 0 & 0 & 0 & 0 & 5 & 5 & 5 & 5 \\
\hline
\end{tabular}

Source: own processing

Table 9: Recommended use of telephone communication route.

\begin{tabular}{|c|c|c|c|c|c|c|c|c|c|c|c|c|c|c|c|c|c|c|c|c|}
\hline \multirow{2}{*}{$\mathrm{F} 2 \mathrm{~F}$} & \multicolumn{4}{|c|}{ owner (O) } & \multicolumn{4}{|c|}{ economist (EC) } & \multicolumn{4}{|c|}{$1^{\text {st }}$ dealer (1D) } & \multicolumn{4}{|c|}{$2^{\text {nd }}$ dealer (2D) } & \multirow{2}{*}{$\mathrm{T}$} & \multirow{2}{*}{$\mathrm{C}$} & \multirow{2}{*}{$\mathrm{Q}$} & \multirow{2}{*}{ LA } \\
\hline & $\mathrm{T}$ & $\mathrm{C}$ & Q & LA & $\mathrm{T}$ & $\mathrm{C}$ & Q & LA & $\mathrm{T}$ & $\mathrm{C}$ & Q & LA & $\mathrm{T}$ & $\mathrm{C}$ & Q & LA & & & & \\
\hline $\mathrm{O}$ & 0 & 0 & 0 & $\mathbf{0}$ & 0 & 17 & 0 & 5.67 & 0 & 12 & 8 & 6.67 & 0 & 1 & 12 & 4.33 & 0 & 30 & 20 & 16.67 \\
\hline $1 \mathrm{D}$ & 0 & 3 & 7 & 3.33 & 5 & 5 & 5 & 5 & 0 & 0 & 0 & $\mathbf{0}$ & 0 & 0 & 7 & 2.33 & 5 & 8 & 19 & 10.67 \\
\hline $2 \mathrm{D}$ & 0 & 0 & 7 & 2.33 & 0 & 0 & 0 & $\mathbf{0}$ & 7 & 7 & 7 & 7 & 0 & 0 & 0 & $\mathbf{0}$ & 7 & 7 & 14 & 9.33 \\
\hline
\end{tabular}

Source: own processing

Table 10: Recommended use of e-mail communication route.

team members do not necessarily mean they do not use this communication route. This means they do not send messages in this direction (they are not initiators of communication) but they can receive messages - see the values above the main diagonal.

The description of the e-mail communication is shown in Table 10. This is the most used communication route as requested by the company owner. This communication route is used for the transmission of 51 weekly messages.

The results of the model show that all team members do not use all types of communication routes but it does not mean they do not use any communication route as the sender or recipient of the message. So, it does not occur the team members would not communicate at all.

Based on the above mentioned results (Table 8, Table 9, and Table 10), the company should use $41 \%$ e-mail communication route, $32 \%$ face-toface communication route, and $27 \%$ telephone communication route.

\section{Discussion}

Communication problems in the selected company confirm the opinion of Zulch (2014) which refers the communication as an important tool in leading of the company. Therefore, it was necessary to design some more efficient manner of coordinating communication to achieve better results and performance inside the company.

To solve this problem, we used an existing environment in which there were known estimates of values entering the model and the transport method by means of which we developed behavioural patterns in utilizing communication routes similarly as Kennedy et al. (2017). Unlike the authors, we focused on communication patterns inside the team. Furthermore, like Zionts (1979), we used the cost and quality as the decision criteria for quantification of communication. We also included the time criterion to cover the basic project management triangle i.e. model of the project constraints. Kennedy et al. (2017) also confirmed 
significance of the view of communication inside the project management triangle.

An impulse for extending our communication model by another variable such as loss of information or absence of information response represents a possible extension of the model. This idea is supported by, for example, Radner (1962). There was mentioned that keeping of messages could be so costly that it would be worthwhile to forget some of them.

Nevertheless, many authors consider communication as one of the reasons of project failure (Kerzner, 2013; Kotzé et al., 2008, etc.), the proposed approach can represent the way of influencing and minimizing this issue. Undoubtedly, the team communication can be promoted not only by training communication skills within the team (Švec, 2013) but also by means of an analysis of the communication patterns (Kennedy et al., 2017; Bavelas, 1950). Changing communication patterns can make communication more efficient, quality, and thus more sparing both time and money. If companies would be aware of the amount of ongoing project communication they could retrospectively evaluate the time and costs spent on the project.

\section{Conclusion}

This article deals with the basic problem of team communication representing a choice of the communication route kind for messages transmitting. In here, the solved complex issue is shown from many perspectives (the perspective of cost, time and quality of communication routes). As an appropriate multiple criteria mathematical model of team communication, the threedimensional transportation model (3DTM) was used. The goal of this model is to find an optimal transportation plan (distribution of messages) between a set of suppliers (senders) and set of consumers (recipients) using different types of transport (communication routes).

The article discusses the case study of communication modelling in the field of agriculture. Specifically, it is the communication model for a small team of agriculture equipment dealers. The case study demonstrated the suitability of the proposed model.

Since the aim of this paper was to show the suitability of the proposed approach, a detailed analysis of the possible formulation of constraints is not mentioned in this article. Generalization of the model formulation is the subject of further research and testing.

Nevertheless, the consideration has to be given to the specific criteria used in the model - whether it may be only cost, time, and quality of the communication routes or whether also other criteria can be used to address many other specific situations.

It is also worth to consider possible extensions of the model constrains by the conditions of excessive information or messages receiving by individual team members. If some team member receives more messages than unconditionally necessary to fulfil a particular task then he may be overloaded by information, which may alternatively follow in his failure in completing the task.

Finally, it is necessary to decide how the criteria coefficients should be obtained. In this case, they were obtained using the method of pairwise comparison but they can be also measured by help of expert estimates. Based on experts' estimation of the criteria coefficients of the communication routes in the company, it is possible to make recommendations for more effective communication or to suggest a more appropriate communication structure.

\section{Acknowledgements}

This article was created within the project "Expanding and Promoting the Transfer of Technologies and Knowledge at the CULS Prague by Implementing 'Proof-of-Concept' Activities", reg. no. CZ.07.1.02/0.0/0.0/16_023/0000111 KZ12 that is jointly funded from the European Union via Operational Programme Prague - Growth Pole of the Czech Republic and it was partially supported by the grant project of the Internal Grant Agency of the FEM CULS Prague "Evaluation of tariff procedures in general insurance", No. 20151036.

Corresponding author:

Ing. Jana Křě̌ková

Department of Systems Engineering, Faculty of Economics and Management,

Czech University of Life Sciences Prague, Kamýcká 129, 16500 Prague 6, Czech Republic

Phone: : +420224 382 374,E-mail: kreckova@pef.czu.cz 


\section{References}

[1] Bavelas, A. (1950) "Communication patterns in task-oriented groups", The Journal of the Acoustical Society of America, Vol. 22, No. 6, pp. 725-730. ISSN 0001-4966. DOI 10.1121/1.1906679.

[2] Bolat, B., Çebi, F., Temur, G.T. and Otay, I. (2014) "A fuzzy integrated approach for project selection", Journal of Enterprise Information Management, Vol. 27, No. 3, pp. 247-260. ISSN 1741-0398. DOI 10.1108/JEIM-12-2013-0091.

[3] Dantzig, G. B. (1963) "Linear programming and extensions", Princeton University Press, N. J.

[4] Hämäläinen, R. P., Luoma, J. and Saarinen, E. (2013) "On the importance of behavioral operational research: The case of understanding and communicating about dynamic systems", European Journal of Operational Research, Vol. 228, No. 3, pp. 623 - 634. ISSN 0377-2217. DOI 10.1016/j.ejor.2013.02.001.

[5] Hoegl, M. and Gemuenden, H.G. (2001) "Teamwork quality and the success of innovative projects: A theoretical concept and empirical evidence", Organization Science, Vol. 12, No. 4, pp. 435-449. E-ISSN 1526-5455, ISSN 1047-7039.

[6] Hsu, J. S. C., Shih, S.P ., Chiang, J. C. and Liu, J. Y. C. (2012) "The impact of transactive memory systems on IS development teams' coordination, communication, and performance", International Journal of Project Management, Vol. 30, No. 3, pp. 329-340. ISSN 0263-7863. DOI 10.1016/j.ijproman.2011.08.003.

[7] Katz, R. and Allen, T. J. (1982) "Investigating the Not Invented Here (NIH) syndrome: A look at the performance, tenure, and communication patterns of $50 \mathrm{R} \& \mathrm{D}$ Project Groups", R\&D Management, Vol. 12, No. 1, pp. 7-20. E-ISSN 1467-9310. DOI 10.1111/j.1467-9310.1982.tb00478.x.

[8] Kennedy, D. M., McComb, S. A. and Vozdolska, R. R. (2011) “An investigation of project complexity's influence on team communication using Monte Carlo simulation", Journal of Engineering and Technology Management, Vol. 28, No. 3, pp. 109-127. E-ISSN 2314-4912, ISSN 2314-4904. DOI 10.1016/j.jengtecman.2011.03.001.

[9] Kennedy, D. M., Sommer, S. A. and Nguyen, P. A. (2017) "Optimizing multi-team system behaviors: Insights from modeling team communication”, European Journal of Operational Research, Vol. 258, No. 1, pp. 264-278. ISSN 0377-2217. DOI 10.1016/j.ejor.2016.08.036.

[10] Kerzner, H. (2013) "Project management: a systems approach to planning, scheduling, and controlling", Eleventh edition, New York: John Wiley. ISBN 978-1-118-02227-6.

[11] Kotzé, B. G., Berry, F. H. and Verster, J. J. P. (2008) "Communication as a crucial element in project management”, Proceedings CD: $12^{\text {th }}$ Pacific Association of Quantity Surveyors (PAQS) Congress on Construction in challenging environments, pp. 16-18.

[12] Lingard, L., Whyte, S., Espin, S., Baker, G. R., Orser, B. and Doran, D. (2006) "Towards safer interprofessional communication: constructing a model of "utility" from preoperative team briefings", Journal of Interprofessional Care, Vol. 20, No. 5, pp. 471-483. DOI 10.1080/13561820600921865.

[13] Melnik, G. and Maurer, F. (2004) "Direct verbal communication as a catalyst of agile knowledge sharing", Proceedings in: Agile Development Conference, 2004. IEEE, pp. 21-31.

[14] Morávek, J. and Vlach, M. (1967) "On the Necessary Conditions for the Existence of the Solution of the Multi-Index Transportation Problem”, Operations Research, Vol. 15, No. 3, pp. 542-45. ISSN 0030-364X.

[15] Saleh, M., Oliva, R., Kampmann, C. E. and Davidsen, P. I. (2010) “A comprehensive analytical approach for policy analysis of sys-tem dynamics models", European Journal of Operational Research, Vol. 203, No. 3, pp. 673-683. ISSN 0377-2217. DOI 10.1016/j.ejor.2009.09.016.

[16] Šubrt, T. (1999) "Multilevel transhipment problems and software realization", Agris.cz - agrarian www portal, Sep. 1999. [Online]. Available: http:/www.agris.cz/clanek/104172/vicestupnovedopravni-modely-a-jejich-programova-realizace [Accessed: 17 Aug. 2017]. 
[17] Švec, V. (2013) "Pilot Run of the Experiential Exercise: Are Students Able to Find and Eliminate Team Loafers?", Proceedings of the $10^{\text {th }}$ International Conference on Efficiency and Responsibility in Education (ERIE 2013), Prague, pp. 603-610. ISSN 1803-1617.

[18] Urbanek, S. (2014) "OLAP Cubes and Logical Models". OLAP Cubes and Logical Models - Open Knowledge Labs, Jan. 2014. [Online]. Available: http://okfnlabs.org/blog/2014/01/20/olap-cubesand-logical-model.html [Accessed: 07 Aug. 2017].

[19] Vlach, M. (1986) "Conditions for the existence of solutions of the three-dimensional planar transportation problem", Discrete Applied Mathematics, Vol. 13, No. 1, pp. 61-78. ISSN 0166-218X. DOI 10.1016/0166-218X(86)90069-7.

[20] Zionts, S. (1979) "MCDM - If not a Roman numeral, then what?", Interfaces, Vol. 9, No. 4, pp. 94-101. E-ISSN 1526-551X, ISSN 0092-2102.

[21] Zulch, B.G. (2014) "Communication: The foundation of project management", Procedia Technology, Vol. 16, pp. 1000-1009. ISSN 1877-7058. 10.1016/j.protcy.2014.10.054. 